\title{
O BIBLIOTECÁRIO COMO PROFISSIONAL DA INFORMAÇÃO E AS REPRESENTAÇÕES DE SUAS COMPETÊNCIAS PROFISSIONAIS E PESSOAIS PARA ATUAR EM BIBLIOTECAS
}

\author{
THE LIBRARIAN AS PROFESSIONAL OF THE INFORMATION AND \\ REPRESENTATIONS OF YOUR PERSONAL AND PROFESSIONAL \\ SKILLS FOR WORK IN LIBRARIES
}

\begin{abstract}
Renée Rosanne Vaz Nina - reneenina@ig.com.br, reneenina@ufam.edu.br Bibliotecária e Docente na Universidade Federal do Amazonas (UFAM) Mestre em Ciência da Informação pela Universidade Federal de Santa Catarina
\end{abstract}

\begin{abstract}
Resumo
O objetivo do estudo foi conhecer as representações de competências socialmente construídas pelo profissional da informação - bibliotecário, inserido no cenário atual da explosão informacional, conseqüência das inovações tecnológicas e da globalização da informação. Essas representações foram coletadas junto aos profissionais atuantes nas bibliotecas da Universidade Federal do Amazonas (UFAM), tendo por base teórica o construcionismo social tratado por Berger e Luckmann (1995), a Teoria das Representações Sociais apresentada por Moscovici (2004) e complementadas pela teoria do processo civilizador de Elias (1994). Metodologicamente, realizou-se a pesquisa em duas etapas. Na primeira, utilizou-se um questionário como instrumento de coleta de informações para caracterização e destaque dos participantes da pesquisa. Na segunda, utilizou-se um roteiro para entrevistar os participantes e proceder à análise de discursos. Assim, empregou-se a técnica do Discurso do Sujeito Coletivo (DSC) tratada por Lefèvre e Lefèvre (2003) e recomendações teóricas de Elias (1998). A análise de discurso, qualitativa e exploratória na coleta das manifestações e opiniões do bibliotecário, possibilitou apresentação do DSC individual de cada questão que por fim se mesclam para constituir o DSC único sobre as competências que o bibliotecário percebe e manifesta com propriedade. Como resultado ressaltou-se alguns fatores de competência neste DSC: a personalidade, o caráter e o amor à profissão; a união do conhecimento, valores e experiências; a criatividade, o comprometimento pessoal e o trabalho em equipe; a atualização continuada profissional e a adaptabilidade à realidade flutuante e ao seu papel social, entre tantas outras citadas.
\end{abstract}

Palavras-chave: Profissional da Informação. Competências. Representação social. Bibliotecários de universidade - Manaus, AM. 


\section{INTRODUÇÃO}

A proliferação da informação em seu dinamismo e multiplicidade de formas de registro e meios de comunicação influencia o desenvolvimento de uma sociedade apoiada em sua transmissão. Da mesma forma influenciam no exercício da profissão de bibliotecário, que antes era calcado na organização bibliográfica. Hoje, exercer a profissão é integrar-se a uma sociedade que transformou a informação em insumo de trabalho. Logo, o profissional tendeu às novas técnicas de comunicação com novos propósitos de trabalho, atuando como um agente de informação da sociedade. No mesmo sentido, o papel das bibliotecas como entidade depositária dos bens culturais produzidos pela humanidade alterou-se como promotora de avanço do conhecimento e tem sido objeto de redefinição e reposicionamento social.

Neste trabalho, entende-se sociedade da informação como um ambiente sócioprofissional transformado pelos vários aspectos contemporâneos que envolvem a informação. Dentre estes aspectos, salienta-se a globalização da economia de mercado, que provocou uma acirrada competição entre as organizações, em busca de mercados e de clientes. Também, a explosão informacional aliada à expansão tecnológica que propicia o aumento da capacidade de acesso e uso da informação com: novos recursos de telemática (software, hardware, tecnologias de acesso, etc.); novos meios e equipamentos de comunicação (CPU, laptops, impressoras digitais, etc.), e; novos suportes de informação (disquete, $C D-R O M$, arquivos on line, $d v d$, pen-drive, etc.).

Essas inovações possibilitaram dispor a informação ao alcance de muitos. Não há mais distâncias intransponíveis para a comunicação e existe a diversidade de acesso à informação. Nesta perspectiva, adapta-se um conceito de biblioteca através da construção de idéias de Blattmann et al. (2003), reconhecendo a biblioteca como unidade de informação atrelada às políticas sociais e econômicas da entidade a que pertence, estando em constante movimento de construção do conhecimento ao acompanhar as mudanças da sociedade.

De fato, o objetivo da biblioteca é recuperar a informação precisa e do modo mais rápido possível, adaptando-se as técnicas bibliotecárias ao avanço tecnológico para tentar compartilhar a informação na mesma velocidade em que surge.

Nesta acepção de mudança, adota-se o conceito de Araripe (1998) referindo-se ao bibliotecário como profissional da informação, no qual afirma que o profissional é interativo e crítico atuante na movimentação da informação na sociedade. Ele passa pelas transformações já citadas na sociedade da informação contemporânea e acompanha a crise do conhecimento, à medida que contribui e participa da reflexão e valoração da informação, do desenvolvimento político ao cultural. Dessa maneira, o bibliotecário é definido como mediador da informação para o usuário, agente da produção ao consumo da informação, com iniciativa e senso crítico-social na construção da realidade, fator de mudança do profissional.

A partir de 2001 a 2003, em estudos para a atualização do currículo e do Projeto Político Pedagógico do Curso de Biblioteconomia na UFAM, muitas informações evidenciaram as mudanças ocorridas na sociedade quanto ao exercício da profissão e, de 
forma mais pessoal, instigaram dúvidas sobre as competências do profissional em questão. Ressaltaram-se, como motivação para realização do trabalho as expectativas da sociedade sobre a formação do profissional da informação observada na produção de publicações oriundas de renomados autores e associações ou eventos, como: Encontros de Diretores de Escolas de Biblioteconomia e Ciência da Informação do Mercosul; Associação Brasileira de Ensino em Ciência da Informação (ABECIN); Arruda, Marteleto e Souza (2000), Barbosa (1998), Blattmann et al. (2003) e Valentim (2000, 2004), entre outros.

Assim também, as controvérsias vividas no exercício da profissão nas bibliotecas e junto ao Departamento de Biblioteconomia na UFAM provocaram os questionamentos quanto ao envolvimento social deste profissional, em particular, sobre suas funções, competências e habilidades, tais como:

- De que forma o profissional da informação percebe as transformações ocorridas na sociedade da informação?

- Existe estímulo para buscar: a formação geral sem prejuízo da formação específica? A educação profissional continuada? A utilização de novos meios tecnológicos no desenvolvimento dos serviços?

- O que o profissional da informação entende por competência profissional de sua área?

Cabe, portanto, buscar-se conhecer a representação das competências profissionais e pessoais que o bibliotecário apresenta como necessárias ao seu desempenho no ambiente bibliotecário. Neste intuito, a seguir se examina brevemente $o$ desenvolvimento da sociedade e da comunicação.

\section{SOCIEDADES EM TRANSFORMAÇÃO}

Em fins do século XVIII, a essencialidade da comunicação é notada quando se dá a fragmentação e a especialização acentuada do processo produtivo. $O$ advento da revolução industrial alterou a estrutura de trabalho fragmentando-a em etapas nas fábricas. A idéia da divisão de trabalho aliou-se à administração estratégica do complexo de comunicação e locomoção (meios e vias fluviais, marítimas e terrestres) convertendo-se em um sistema de crédito segundo Mattelart e Mattelart (2003). Intensifica-se e se incentiva o intercâmbio e acesso às informações essenciais que favoreça o progresso das regiões com o desempenho e o incremento econômico.

$\mathrm{Na}$ sociedade descrita por esses autores há diversidade e amplidão de formas e perspectivas de comunicação entre o técnico e o cultural, entre o individual e o social. $\mathrm{O}$ fluxo e o refluxo de dicotomias e oposições em correntes, tendências e contextos históricos impossibilitam o desenvolvimento linear. Isto é, predispõe-se a valorização do descobrimento de informações e de conhecimentos contextuais que volta e meia retornam ao momento de análise.

Neste contexto, a sociedade pós-industrial é caracterizada por De Masi (2003) por sua produção ser realizada quase que exclusivamente por máquinas e da existência de nova divisão de conhecimento, poder e trabalho, de forma que uns produzem e outros experimentam. O conhecimento detém uma ação central junto ao plano social, 
fragmenta-se e se diversifica alicerçado nas tecnologias usadas nas organizações. Portanto, os saberes técnico ou profissional apoiados nas tecnologias e na distribuição de serviços são efeitos significativos da sociedade pós-industrial. Dessa forma, as competências profissionais têm-se modificado e se firmado conforme a necessidade de bens e serviços sentidos pela sociedade (FREIDSON, 1998).

Já estudos de Tarapanoff, Araújo Júnior e Cormier (2000) salientam que na sociedade da informação se iniciaram as principais mudanças na estrutura do sistema informacional.

Enfim, para conceituar a sociedade da informação apoia-se na afirmação de Tarapanoff (2001, p.39) de que é um ambiente da informação composto por um sistema de processos sociais transformador do desenvolvimento industrial como modelo produtivo, onde o desenvolvimento informacional é baseado na aplicação "[...] do conhecimento como insumo crítico [...]". A estrutura da sociedade da informação incentiva uma busca aos novos referenciais sociais, econômicos, tecnológicos e culturais, que incitam a sociedade e as organizações às mudanças, por meio de adaptações e variações de ações e atividades necessárias à nova realidade. A aliança do sistema informacional às inovações tecnológicas contribui com um sistema dinâmico e transformador de produção e circulação de informação.

Busca-se a seguir fundamentar as práticas profissionais de gestão do bibliotecário sobre conhecimento e competências.

\section{CONHECIMENTO E COMPETÊNCIA}

Ao tratar das transformações na organização social do conhecimento, no período inicial da era moderna, na Europa, Burke (2003) considera o conhecimento como uma questão evidente ou particular da informação com possibilidades econômicas e sociais. De outra forma, Bell (1977) apresenta um conceito mais completo, pois o autor define conhecimento como um conjunto de conjecturas elaboradas de ocorrências ou concepções refletidas ou experimentadas, transmitidas a outrem por algum meio de comunicação estruturado. Nesse sentido, o conceito adotado neste trabalho para conhecimento é o de informação contextualizada, produzida e absorvida pelo indivíduo ou pela organização, e miscigenada ao seu saber anterior (VIEIRA, 1993).

Os estudos sobre as perspectivas de construção desse conhecimento evoluíram, há diferenças nas abordagens e nos interesses pela história do conhecimento que vêm passando de uma forma intuitiva a uma forma sistemática.

Nesse sentido, Burke (2003) vem contribuir com esclarecimentos sobre a teoria do conhecimento quanto à organização, desenvolvimento e também a arborescência do conhecimento, mas a idéia de que a realidade é influenciada por seu meio social não é novidade. Estudos de classificação do conhecimento partiram da arborescência de hierarquias e distinções de troncos e galhos do conhecimento para o conjunto de saberes abordado pelas várias ciências, como: Antropologia, Filosofia e Sociologia do conhecimento como parte e como um todo. 
Salienta-se estudiosos da área de administração interessados na aplicação do conhecimento ao cotidiano do profissional como Probst, Raub e Romhardt (2002), que apontam a complexidade e a amplitude do uso do conhecimento profissionalmente. Estes autores confirmam o poder das pessoas na geração e desenvolvimento do conhecimento, condicionando a existência do conhecimento ao ser humano, de maneira que não há conhecimento sem seu envolvimento. O conhecimento é representado por linguagem, sinais, símbolos ou caracteres táteis, sonoros ou visuais, de acordo com o conjunto de saberes criado pelo homem, e sob cuja forma ele o apresenta, o reconhece e o compartilha, pois o conhecimento advém da necessidade do indivíduo sobreviver e se comunicar, seja no seu dia-a-dia, seja em sua vida profissional.

Para Polanyi (1983) não há conhecimento objetivo e absoluto, o conhecimento é construído por seres humanos que possuem valores e experiências pessoais e sociais, que influem e são influenciados a cada fenômeno social, portanto, enriquecem com cada nova idéia ou situação adotada. Conseqüentemente, neste estudo se define $o$ conhecimento tácito como: originalmente constituído pela mente humana com seus sentimentos e sensações, intangível, pessoal e implícito ao indivíduo, alia o conhecimento intelectual ao prático e está em freqüente transformação e movimento, então, no momento seguinte a sua explicitação, terá mudado outra e outra vez, e assim por diante (POLANYI, 1983).

Sveiby (1998) faz uma comparação entre conhecimento e competência com relação à capacidade de saber. Especifica o conhecimento como a capacidade de saber e aprender continuamente e a competência como a capacidade de identificar nas informações as formas e regras de ação com a segurança de um especialista. Aprimora a competência com a perícia, que no caso, possibilita transformar, readaptar e inovar as ações. Assim como o conhecimento é a base para a competência, a perícia é o diferencial de inovação e segurança de ação que o profissional competente desenvolveu. Indica o alto nível de conhecimentos reagentes e intrínsecos ao indivíduo que possibilitam o imediatismo e a precisão de reação.

Neste caso o conhecimento tácito é uma ferramenta fundamental que orienta como se deve agir ou reunir novos conhecimentos para realizar uma ação focalizada. Segundo Polanyi (1983), a percepção e apreensão do conhecimento concentram o poder de criatividade e o processo comportamental do homem. No entanto o conhecimento inerte armazenado em qualquer suporte sem influir qualquer reação não interage com o seu meio e não se desenvolve. Portanto é o compartilhamento do conhecimento que o desenvolve e recria novas competências, é quando de fato se está ativo.

Segundo Zarifian (2001), é na década de 1980 que a interseção de conhecimentos e habilidades profissionais e sociais estimula o desenvolvimento de competências essenciais no indivíduo. O autor afirma que o indivíduo deve dispor de seu potencial de conhecimento em prol dos objetivos e estratégias de competitividade da organização, através dos pequenos grupos. Os potenciais de conhecimentos e habilidades individuais são cooptados, e se transformam em competências ao compartilharem e interagirem com empenho, com responsabilidade e comprometimento. 
Zarifian (2003, p.137) ressalta três fatores de competência - articular pessoas, compartilhar e responsabilizar-se - como primeiros preceitos à responsabilidade e ética profissional. Considerando esses fatores, adota-se o conceito dado por Zarifian (2003, p.137) quando conclui que a competência "[...] é a tomada de iniciativa e o assumir de responsabilidade do indivíduo sobre problemas e eventos que ele enfrenta em situações profissionais", de certo que toda atitude profissional segue a percepção ética e moral de responsabilidade.

Em conseqüência, adota-se a definição elaborada no Medef $(1998)^{1}$ proposta em Zarifian (2001, p. 66) para competência profissional como marca de uma mudança organizacional e social no trabalho: "[...] é uma combinação de conhecimentos, de saber-fazer, de experiências e comportamentos que se exerce em um contexto preciso. [...]". Em síntese, este conceito afirma que o essencial é descobrir como interagir o saber-fazer do profissional com as necessidades de uma situação concreta e inesperada; como articular as habilidades e a qualificação profissional e social do indivíduo ou grupo com a produção segura e singular de uma solução satisfatória e inovadora para a organização. Neste contexto, adota-se este conceito, primeiro, porque é balizado na mudança de comportamento social associado ao trabalho na organização, o que se assemelha à situação do bibliotecário em seu ambiente de trabalho. Segundo, porque a representação das competências profissionais do bibliotecário é o objeto desta pesquisa.

$\mathrm{Na}$ tentativa de compreender as mudanças ocorridas com a postura social e as funções deste profissional, busca-se evidenciar as competências dos bibliotecários, sob a perspectiva das representações sociais que eles próprios constroem, seguindo-se uma revisão das teorias relacionadas à cotidianidade ou a sociologia do conhecimento, representações sociais e processo social.

\section{A SOCIOLOGIA DO CONHECIMENTO E OS IMPACTOS CIVILIZADORES}

Para compreender a construção da realidade da sociedade através do conhecimento dos indivíduos, é utilizada a concepção dos sociólogos Berger, Luckmann e Elias, cujo alcance de seus pensamentos envolve as disciplinas da Sociologia do Conhecimento e da Psicologia Social, além da influência do "processo civilizador", respectivamente.

Berger e Luckmann (1995) analisam os mesmos fenômenos, sob diferentes concepções empíricas ou subjetivas, por meio de comentários críticos e sob múltiplas visões, em busca de esclarecer seu interesse de investigação, que é a construção social da realidade. Seu objeto de pesquisa é a sociedade com suas realidades: objetiva, quando analisam a sociologia do conhecimento; e subjetiva, quando analisam sua consciência exclusiva, em que a junção das duas realidades das sociedades propicia a teorização da psicologia social. Em suma, os autores consideram que a sociologia do conhecimento analisa os fenômenos do dia-a-dia que contêm o conhecimento social e compõem a sociedade e seu comportamento. A sociologia do conhecimento é o estudo da seqüência

\footnotetext{
1 Movimento de Empresas da França (Medef), ex-CNPF, Jornadas Internacionais de Deauville, 1998: objetivo competências, t.1, out. 1998.
} 
de situações (o caminho percorrido) que levam até os acontecimentos, é a compreensão de como as ocorrências influenciaram ou se desenrolaram na sociedade.

Ao se observar as mudanças da sociedade sob a ótica de Elias (1994, p. 13) o "processo civilizador" enfoca os "[...] tipos de comportamento considerados típicos do homem civilizado ocidental". O autor se refere ao processo civilizador como processos contínuos, dinâmicos e transformadores de comportamentos, valores pessoais e sociais do homem, em que a verdade e o "civilizado" de cada sociedade são relativos a si próprios, em seu próprio tempo e espaço. Nesse intuito, procura-se a seguir esclarecer os fenômenos sociais como objetos formadores de representações sociais, que interferem na construção do saber do homem afetado pelas mudanças no ambiente e na sociedade que o cerca.

\section{REPRESENTAÇÕES SOCIAIS (RS)}

O exame das propostas de Durkheim (2003) e de Moscovici (2004) implica a compreensão sócio-psicológica da realidade no desenvolvimento das teorias sobre as representações do coletivo e sociais, respectivamente. Alia-se a estas a proposta da teoria do descomprometimento da natureza humana desenvolvida por Elias (1998), que enfoca a alienação e o envolvimento do pesquisador, ao se inserir como parte do meio investigado, mas não participante.

O fenômeno social em representações do coletivo de Durkheim (2003) precede a teorização do fenômeno social de Moscovici (2004), que instaura um conflito, por combinar conceitos da Sociologia com conceitos da Psicologia, a ponto de enxergar os fenômenos sociais como RS. A Psicologia do conhecimento se preocupa em conhecer o desenvolvimento do homem em sua conduta e intelecto para partilhar um conhecimento, enquanto a Sociologia do conhecimento se preocupa em observar e descrever o processo em que o fenômeno acontece, como as etapas que este conhecimento atravessa para sua construção e aceitação na sociedade.

Para Durkheim (2003), a idéia de representação coletiva quer dizer a associação de indivíduos que vivem numa realidade influenciada pelo coletivo, pelo sistema corporativo estático de uma sociedade, não pelo ajuntamento de indivíduos, mas sim pela idéia interiorizada, autônoma e coercitiva da sociedade como um todo, independente da vontade individual.

Por outro lado, Moscovici (2004, p. 49) optou pelo termo "social" para salientar a dinamicidade da sociedade, principalmente ao enfocar a transformação social mediante o senso comum. Isto significa que os processos de mudança e preservação na vida dependem da ancoragem e objetivação que uma minoria impõe a essa sociedade. $O$ senso comum predomina através dos hábitos sociais que o homem vivencia em seu meio ambiente e em suas associações de comunicação, bem como em seus pensamentos e nas opções que compõem sua realidade compartilhada. Moscovici (2004) propõe o estudo sobre o fenômeno representacional, não como um conceito, mas como uma teoria; num entrelace sociopsicológico novas perspectivas surgem aos poucos numa parte dessa sociedade com crescente envolvimento do homem, consciente ou inconscientemente, até se tornar um ponto em comum, manifestações dinâmicas do comportamento e do cognitivo de um determinado grupo social. 
Para Jodelet (2001), a necessidade das pessoas de conviver com outras pessoas, situações ou pensamentos estimula a criação das representações no mundo em que elas vivem. As circunstâncias de adequação física ou intelectual vividas na procura de solucionar quaisquer problemas surgidos influem no comportamento e na interpretação de sua realidade na sociedade. Sendo assim, a representação é social e essencial à sua sobrevivência.

Moscovici (2004) diferencia as RS pela capacidade de imaginação e inovação da sociedade moderna, em sua hierarquização de poder e idéias divergentes, que agrupam ou desagregam partes desta sociedade em pequenos sensos comuns, enquanto as representações coletivas são estáticas e homogêneas à sociedade.

Em síntese, as representações influem na autonomia e no condicionamento da cognição do homem, por meio de convenções (condicionamentos, experiências) e prescrições (imposições científicas, religiosas, tradições). Semelhante a Elias (1994), Moscovici (2004) afirma que as civilizações são distribuídas e mutáveis, co-existem e transitam em várias etapas, repetindo-se e inovando, de geração em geração. Por isso, defende o símbolo convencional ou prescrito. O simbolismo convencionado pelas associações de idéias, que as pessoas incutem em objetos e ações, envolve a realidade dessas pessoas, e é aceito como verdade na sociedade. Por exemplo, a mão fechada, com o polegar apontado para cima, é um sinal positivo. É o mesmo caso do simbolismo prescrito, mas este acontece com determinações sociais impostas e re-citadas por tradições de gerações, por exemplo, os tabus que regem o comportamento feminino, o materno ou o masculino.

Toda representação social surge da interação humana que influi mudanças na natureza do comportamento do homem em sua coletividade. Portanto, as RS são as expressões, o produto ou a associação criado e transmitido por pessoas ou grupos de pessoas, que desenvolvem um pensamento alicerçado nas convenções e tradições comuns de seu ambiente. O compartilhamento e comunicação destes pontos comuns adquirem uma identidade própria e transcorrem como nova realidade social em RS científicas, religiosas, culturais e profissionais, sendo esta última o interesse desta pesquisa.

\section{METODOLOGIA E AMBIENTE DA PESQUISA}

No intuito de garantir a imparcialidade da pesquisa, visto que esta pesquisadora é parte integrante dos profissionais do meio investigado, empregou-se a teoria do envolvimento e do distanciamento da natureza humana de Elias (1998) como apoio para considerar as características e as manifestações dos profissionais com distanciamento da pessoalidade. Salienta-se o uso do Discurso do Sujeito Coletivo (DSC), técnica criada por Lefèvre e Lefèvre (2003), em que os pesquisadores vislumbram caminhos para elaborar e organizar instrumentos de coleta e tratamento, que sejam adequados às pesquisas de representações sociais inerentes aos discursos de sujeitos que constituem um coletivo. A técnica usada consiste num sistema de observação e análise, aplicada à coleta de várias manifestações verbais ou escritas distribuídas em: expressões-chave $(\mathrm{ECH})$, idéias centrais (IC) e ancoragem (AC) que se transformam em um único 
discurso da realidade coletiva. Por isso mesmo, é chamada de Discurso do Sujeito Coletivo.

A coleta de dados para a pesquisa deu-se nas bibliotecas universitárias congregadas no órgão suplementar da Universidade Federal do Amazonas (UFAM), SISTEBIB (Sistema de Bibliotecas da UFAM). O sistema possui um acervo de todos os formatos e das áreas do conhecimento. Através da implantação do Sistema de automação Pergamum contempla as principais funções de uma biblioteca, funcionando de forma integrada, desde a aquisição do material até controle do empréstimo e devolução. A estrutura de trabalho se constitui da Biblioteca Central (uma diretoria e cinco divisões) e das oito bibliotecas setoriais em Manaus, mais seis bibliotecas no interior do Estado do Amazonas (SISTEBIB, 1997). A população do SISTEBIB é de 60 servidores, tendo 38 bibliotecários, dos quais 31 profissionais estão atuando e 22 funcionários, entre assistentes, auxiliares administrativos e de apoio.

É, portanto, através da análise do discurso de uma população constituída por bibliotecários, que se torna possível espelhar a opinião e reflexão desse tipo de profissional e sociedade, nesta pesquisa. Optou-se pela investigação qualitativa das representações das competências que este profissional professa.

\section{PROCEDIMENTOS METODOLÓGICOS E RESULTADOS}

Realizou-se a pesquisa em duas etapas. Na primeira, utilizou-se o Questionário de Caracterização do Bibliotecário (NINA, 2006, p.168) como instrumento de coleta de informações para caracterização e destaque dos participantes da pesquisa. Na segunda, utilizou-se um Roteiro Semi-Estruturado de Entrevista ao Bibliotecário (NINA, 2006, p.170) para entrevistar os participantes e proceder à análise de discursos. Participaram da caracterização 28 bibliotecários - assinalados aleatoriamente com letras maiúsculas do alfabeto -, dos quais 11 foram destacados para a entrevista de acordo com os critérios de formação, tempo e experiências e trabalho.

Os dados coletados na entrevista foram tabulados e analisados com o uso da técnica do Discurso do Sujeito Coletivo (DSC) tratada por Lefèvre e Lefèvre (2003), que condensou as idéias do grupo em um único discurso. Este foi apresentado como a expressão discursiva sintética dessa representação profissional e social, e, posteriormente, foi interpretada, levando-se em conta as teorias do construcionismo e das RS.

\subsection{A Caracterização do Bibliotecário atuante no SISTEBIB em 2005}

Pela coleta dos dados se estabeleceram informações coletivas e individuais quanto à formação continuada e participação do bibliotecário: em cursos, atualizações, eventos e sobre a atuação profissional:

a) Quanto à formação - 28 bacharelados em Biblioteconomia (Tabela 1), apenas 1 não foi graduado na UFAM, e somente 3 profissionais são do sexo masculino. Há 5 profissionais do gênero feminino que possuem uma segunda formação de nível superior (Tabela 2). 
Tabela 1 - Período de conclusão de curso de Biblioteconomia - 1969/2004 nível superior

Tabela $2-2^{\text {a }}$. Graduação de

\begin{tabular}{l|l}
\hline Bibliotecários & $\begin{array}{l}\text { Períodos de conclusão de curso de acordo com as } \\
\text { mudanças curriculares }\end{array}$ \\
\hline $6 \ldots \ldots \ldots \ldots \ldots \ldots \ldots \ldots . .$. & $1969-1979$ \\
$11 \ldots \ldots \ldots \ldots \ldots \ldots \ldots . .$. & $1980-1989$ \\
$5 \ldots \ldots \ldots \ldots \ldots \ldots \ldots \ldots . .$. & $1990-1992$ \\
$6 \ldots \ldots \ldots \ldots \ldots \ldots \ldots \ldots . .$. & $2000-2004$ \\
\hline
\end{tabular}

\begin{tabular}{l|l}
\hline Bibliotecários & $2^{\mathrm{a}}$. Graduação \\
\hline $1 \ldots \ldots \ldots \ldots \ldots \ldots . .$. & Contabilidade \\
$1 \ldots \ldots \ldots \ldots \ldots . .$. & Economia \\
$2 \ldots \ldots \ldots \ldots \ldots . .$. & Serviço social \\
$1 \ldots \ldots \ldots \ldots \ldots \ldots .$. & TecnologiaemTopografiaeEstradas \\
\hline
\end{tabular}

No caso de pós-graduados, há 22 profissionais em nível de especialização (Tabela 3).

Dentre estes, 15 possuem cursos na área de CI, e 1 destes possui dois* cursos.

Tabela 3 - Cursos de pós-graduação na área de CI em nível de especialização freqüentados pelos profissionais do SISTEBIB $-1978 / 2003^{2}$

\begin{tabular}{|c|c|c|c|}
\hline Bibliotecários & CURSO & INSTITUIÇÃO & ANO \\
\hline & Administração de Bibliotecas & UFAM & 1978 e 1987 \\
\hline & Serviços de referência & UFAM & 1985 \\
\hline ….................. & Sistemas de informações voltados para o usuário* & UFAM & 1985 \\
\hline 1 1................................ & Organização de Arquivo & USP & 1986 \\
\hline 1 1............................ & Formação da Base de Dados - InformAM* & UFPA & 1991 \\
\hline 7 .............................. & Gestão da informação & UFAM & 1996 \\
\hline $2 \ldots \ldots \ldots \ldots \ldots \ldots \ldots \ldots \ldots \ldots$ & Arquivologia & UFAM & 2001 e 2003 \\
\hline
\end{tabular}

Verifica-se que há diversidade de interesses, seguindo os enfoques do desenvolvimento da CI voltados aos serviços das bibliotecas e da instituição. De forma que, 8 participantes possuem pós-graduação em outras áreas afins, como confere a tabela 4:

Tabela 4 - Cursos de pós-graduação em áreas afins em nível de especialização freqüentados pelos profissionais do SISTEBIB - 2001/ $2005^{3}$

\begin{tabular}{|c|c|c|c|}
\hline Bibliotecários & CURSO & INSTITUIÇÃO & ANO \\
\hline $2 \ldots \ldots \ldots \ldots \ldots \ldots \ldots \ldots \ldots \ldots \ldots$ & Marketing empresarial & UFAM & 2001 \\
\hline 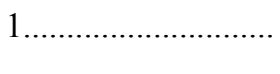 & Instrumento de gestão para organização & UFAM & 2004 \\
\hline ……............. & Metodologia do Ensino Superior & Fac. D. Bosco & 2004 \\
\hline 1 & Administração de empresas & FGV/ISAE & 2005 \\
\hline $2 \ldots \ldots \ldots \ldots \ldots \ldots \ldots \ldots \ldots \ldots$ & Monitoramento e Inteligência Competitiva & UFAM & 2005 \\
\hline $1 \ldots \ldots .$. & Planejamento Estratégico & UFAM & 2005 \\
\hline
\end{tabular}

b) Quanto aos cursos de aperfeiçoamento e atualização - pouco menos da metade dos 28 , num total de 12 , participaram de atualizações na área de CI, dos quais 3 também

Fonte: NINA, 2006, p. 110. Quadro 8.

Fonte: NINA, 2006, p. 111. Quadro 9. 
fizeram cursos de atualização em áreas afins, enquanto 2 outros partícipes fizeram cursos somente em áreas afins. Os participantes também argumentaram à dificuldade de existência de cursos na área de CI na cidade de Manaus, mas, mesmo assim, têm demonstrado interesse em sua educação continuada, por meio de cursos formais.

c) Quanto ao comparecimento a eventos - nos dois anos anteriores ao início da pesquisa 20 profissionais confirmaram presença em eventos em Manaus, e apenas 2 foram a eventos externos à UFAM e ao estado do Amazonas. Os participantes sempre argumentam sobre o alto custo e a dificuldade de financiamento para deslocamento aéreo aos outros estados, a fim de participarem de mais cursos e eventos e garantir uma educação continuada, atualização e intercâmbio profissional e social. Um empecilho é a existência de apenas uma rodovia para fora do estado do Amazonas, BR174 (Manaus/AM - Boa vista/RR).

d) Quanto à educação continuada em cursos formais - apurou-se que a maioria dos participantes se preocupava em realizá-los, apenas 6 não fizeram pós-graduação (especialização). Destes seis, cinco são antigos funcionários, e o sexto é recém formado e incorporado ao SISTEBIB junto a outros cinco que já possuíam ou freqüentavam pósgraduação.

e) Quanto à atuação profissional - averigua-se que esse grupo de profissionais, em sua totalidade, trabalhou nas áreas da: referência e organização da biblioteca; processamento do acervo; seleção do acervo; política de aquisição e/ou desbaste do acervo nas bibliotecas; atendimento a usuários.

f) Quanto ao conhecimento adequado - observa-se que o profissional atuou em diversas atividades, vários níveis e campos de ação da biblioteca, tanto por exercer a chefia, quanto por gostar de sua atividade. Já possuía conhecimento adequado, quando da assunção de suas funções, o que não impediu que muitos procurassem participar de treinamentos ou cursos por iniciativa própria. Além disso, os profissionais confirmaram que o SISTEBIB tem proporcionado treinamentos específicos ao desenvolvimento de atividades, tais como: processamento técnico, acesso às bases de dados e portais de pesquisa na web e levantamentos para usuários. Isto demonstra o interesse em continuar sua educação profissional, apesar das dificuldades já mencionadas, e da própria universidade não possuir estrutura para oferecer os cursos/treinamentos necessários ao desenvolvimento contínuo do bibliotecário, como argumentado por vários profissionais.

Conseqüentemente, a caracterização distinguiu o bibliotecário, como participante das atividades da biblioteca e da instituição. Evidenciou sua inclusão e conhecimento nas atividades do SISTEBIB, destacou o seu ajustamento cognitivo, prático e social às perspectivas das competências necessárias, por sua própria experiência, no exercício da profissão, tendo em vista a diversidade de sua atuação em projetos, campanhas e programas de ações múltiplas das bibliotecas da UFAM.

\subsection{A Amostra e os instrumentos de pesquisa}

Após a comparação dos dados dos 28 bibliotecários caracterizados na $1^{\mathrm{a}}$. etapa com os critérios de seleção, verificou-se que 22 participantes possuíam: 10 anos ou mais no exercício da profissão como bibliotecário e 6 anos ou mais no exercício da função e na UFAM. Dentre estes, somente 11 atuaram em mais de uma linha de trabalho da UFAM, os quais foram entrevistados na $2^{\mathrm{a}}$. etapa. 
Observa-se que quase todos bibliotecários possuem pós-graduação (especialização), além de terem atuado em vários níveis e tipos de atividades da biblioteca. Isto se confirmou diante dos relatos, que duraram em média quinze minutos, e foram transcritos com supressões representadas por colchetes, para resguardar o sigilo dos participantes. Desses 11 informantes, houve uma única desistência, o que não reduz o valor do DSC final obtido.

Considera-se que a execução da coleta e a análise dos dados foram satisfatórias para o pesquisador. Os instrumentos de coleta, bem como a técnica de análise de discurso, embora sejam trabalhosos, foram de rápido manuseio e compreensão, facilitando a execução do trabalho. Acredita-se que sua realização ocorreu da melhor maneira possível, e foi recriando novas expectativas e satisfação ao observar a forma prazerosa dos participantes na pesquisa. Pareceu que a maioria desejava falar de sua profissão, de suas realizações e de suas dificuldades no ambiente de trabalho.

Os instrumentos de coleta de dados elaborados para a pesquisa realizada em duas etapas: o questionário na $1^{\mathrm{a}}$. etapa e o roteiro para a entrevista na $2^{\mathrm{a}}$. foram idealizados de acordo com o objetivo e os aspectos sociais da pesquisa.

A primeira etapa visou à caracterização da população. Para levantar os dados dos bibliotecários e selecionar os que respondessem aos critérios definidos para participação foi elaborado o "Questionário de Caracterização do Bibliotecário" com 31 questões fechadas. Esse questionário foi baseado, principalmente, no perfil e nas competências do profissional da informação propostos no documento do IV Encuentro de Directores de Escuelas de Bibliotecología y Ciencia de la Información del Mercosur; anexo 3 (apud VALENTIM, 2000, p.17-21), ocorrido na cidade de Montevidéu, em maio de 2000. Esta proposta foi ressaltada, porque foi fruto de um estudo debatido por profissionais de vários países, sobre as contingências acadêmicas e mercadológicas, e que dispôs claramente as necessidades de formação que a sociedade requer desse profissional.

$\mathrm{Na}$ segunda etapa, para a realização das entrevistas, seguiu-se o "Roteiro SemiEstruturado de Entrevista ao Bibliotecário", constituído de 5 perguntas abertas.

Os demais procedimentos e outros resultados permitiram a obtenção de respostas para a construção e interpretação do discurso do sujeito coletivo (DSC).

\section{DISCURSO DO SUJEITO COLETIVO (DSC)}

Feitos alguns recortes no DSC resultante das manifestações dos bibliotecários, destacam-se os trechos abaixo que figuram nas representações sociais referentes às suas competências pessoais e profissionais:

As fundamentais características da competência são a personalidade e o caráter de um profissional, que tem consciência da sua especialidade... ter amor pela profissão, ... conhecimento do serviço que você está prestando à comunidade... para atender as necessidades dos usuários, ... [ser] voltado ao papel social...

A educação formal é importante e o aperfeiçoamento da nossa profissão. Não é só estudo! ... leitura é atualização! É a informação constante. 
Competência envolve a capacidade que a pessoa tem de fazer as coisas sob determinado aspecto... É planejamento e execução.

O ponto principal é... ter conhecimento de causa e discernimento detalhadamente de todo o processo do setor em que atua. Para então aplicar o conhecimento que eu tenho sobre a minha profissão, teórico e empírico... trabalhando com habilidade, imaginação e criatividade... é a junção de conhecimento, de prática, dedicação, organização e planejamento, para a execução de um objetivo final

É preciso ter bom senso e a sensibilidade na hora de agir, não se limitar... usar aquela orientação e a informação, em busca de uma forma mais plausivel de determinar aquela coisa.

Competência é... o que me compete... é a minha responsabilidade... É a eficácia daquilo que está sob a minha competência.

É ter uma visão geral de toda a realidade dele e é ter ética.

Competência envolve interdisciplinaridade... saber ouvir, além de falar... para haver o feedback e o senso crítico.

Nós precisamos ter as nossas competências aprimoradas todo tempo... conhecimento especializado... com cursos específicos... de uma outra língua... de informática... de atualização, de mestrado...

... eu uso dedicação, organização, assiduidade. Trabalhando, especialmente lá no interior... o mínimo que se faça é assim propagado! ... A gente tem nisso motivação que alguém gostou, então se dedica mais.

... Juntam-se, vira uma equipe coesa, e sai! É um trabalho de equipe que dá resultado.

Para eu atender o meu usuário... toda minha formação é importante. Eu tenho habilidade, tenho que saber classificação, tenho conhecimento do acervo... Porque o usuário, quando chega aqui, não tem conhecimento algum do assunto ou do acervo.

Tenho que estar centrado... para eu saber que eu posso achar o que ele quer, para me comunicar... paciência, educação. O tato é uma das competências que o bibliotecário tem que ter ao lidar com o usuário.

... tem que ser político... ter criatividade... fazer uma análise de si, para saber se está atendendo bem, se está disseminando informação adequada, no momento exato.

... Tem-se que ter parceria... bom relacionamento, precisa mostrar interesse e motivar os seus colegas de trabalho a ter esta criatividade, ...

As competências profissionais são da equipe de trabalho, não só o ambiente de trabalho interno, mas do ambiente de estrutura institucional... A criatividade é assim essencial, para poder se trabalhar com os poucos recursos que se tem.

Somos o gestor da informação e o elo do conhecimento e do saber com o pesquisador. A gente sempre trabalha junto de outros profissionais, nunca sozinho.

... Todas as competências que atuam aqui têm que ter conhecimento do sistema de informação e de informática...

Profissional competente é aquele que atinge patamares mais altos... de forma positiva... com o bom atendimento, com a interdisciplinaridade... do relacionamento com os docentes, com a família universitária. ... é o que conseguiu alcançar os objetivos que ele planejou com sua vontade de progredir, a disponibilidade em sempre querer aprender e sempre fazer melhor... ser uma pessoa afeita ao diálogo, mas ele tem que ter preparo, ter firmeza naquilo que informa e saber colocar sua profissão à disposição, tanto para o usuário, quanto para a instituição, ou fora da instituição... A competência ... é a expressão do conhecimento.

O profissional competente... tem a capacidade de saber fazer e realizar o seu trabalho dentro daquilo que está ao seu alcance... mesmo quando não tem as condições adequadas. $E$ ultrapassar seus próprios limites.

Um profissional é competente quando procura fazer especialização, fazer pósgraduação... Tem que acompanhar a modernidade e o avanço tecnológico, para poder prestar informação na hora certa, precisa e adequada. Criar condições, inventar, tenta... tem que correr atrás, com criatividade e desprendimento. 
Com base no DSC se elencam algumas representações de competências pessoais e profissionais e representações da atualização profissional recorrentes no discurso construído como:

a) Pessoais - personalidade, caráter, amor à profissão; equilíbrio, bom senso e sensibilidade; consciência, assiduidade, dedicação, imaginação, iniciativa, criatividade e comprometimento pessoal; trabalhar em equipe, ouvir, falar, ser afeito ao diálogo, respeitar os limites do colega, motivar, mostrar interesse, ter paciência, procurar bom relacionamento, ser político; conhecimento básico, experiências e vivências; responsabilidade; ética; educação doméstica; ter vontade de progredir; organização, eficiência, capacidade, habilidades práticas e cognitivas; disponibilidade, desprendimento, flexibilidade;

b) Profissionais - senso crítico; conhecimento específico e teórico profissional individual e de equipe e geral do ambiente (trâmites, rotinas, ações); habilidades técnicas, ter preparo, firmeza, interdisciplinaridade; responsabilidade; educação formal; saber fazer, aprender, procurar fazer melhor, realizar seu trabalho, ultrapassar limites, criar condições, inventar; eficácia, capacidade de planejar, executar, inovar para evitar ou solucionar problemas, alcançar objetivos planejados; ser agente facilitador do acesso a informação;

c) Atualização profissional - conhecimento geral da realidade; sinergia, interdisciplinaridade, adaptabilidade à realidade flutuante e a seu papel social; aprimorar conhecimento em línguas, informática, pós-graduação, comunicação, cursos variados além da CI; informação constante e variada, conhecimento do ambiente, processos, trâmites e objetivos internos e externos ao serviço ou instituição; atualização continuada profissional e social; gestão da informação, conhecimento do sistema de informação; atingir altos patamares de forma positiva; procurar bom relacionamento com a comunidade universitária, a modernidade e o avanço tecnológico, entre outras tantas citadas.

Ao relacionar as representações com discursos da Ciência da Informação sobre formação e competências na sociedade da informação e as teorias sociais apresentadas verifica-se a interação cultural e intelectual ao alcance das pessoas e as políticas de modernização que propiciam a sobrevivência das organizações. Mesmo sem conhecimento das teorias do construcionismo social e levantamentos sobre a modernidade das Ciências da Informação os manifestantes ancoraram suas representações; dentre elas, em Freidson (1998) que associa a aceitação da profissão com as adequações à evolução das necessidades da sociedade e à regulamentação oficial da profissão; ou descrevem a dialética e a predisposição que envolve os bibliotecários, no conhecimento de seu ambiente de trabalho abordada por Vieira (1993). Também relacionam os fatores de responsabilidade, de ética e de trabalho em equipe salientados por Zarifian (2003). Ainda, destacam a qualificação e adequação dos cursos acadêmicos do profissional da informação, e sugerem a educação continuada como recurso para acompanhar a explosão informacional e seus inovadores meios de transmissão, a atualização e a criatividade que alguns pesquisadores da CI, como Arruda, Marteleto e Souza (2000), Barbosa (1998) e Valentim (2000) enfatizam como necessárias ao profissional. Para que tal aconteça há necessidade contínua de atualização e 
compartilhamento do conhecimento pelo profissional para melhorar suas habilidades técnicas e o desenvolvimento da organização. $O$ processo de aplicação das competências é determinante para adequações nos procedimentos de trabalho, revistos e re-adaptados de forma que permita uma nova estratégia para a organização evoluir continuamente. Dessa maneira, o bibliotecário deve saber usar as tecnologias da informação disponíveis no momento da necessidade. A associação de Administração, Tecnologia da informação (TI), Biblioteconomia, Comunicação e outras áreas de conhecimento destacam ou favorecem as práticas de serviço, possibilitando saber quais as informações são ou serão necessárias para orientar o bibliotecário nas bibliotecas à realidade do meio ambiente externo e interno. A interdisciplinaridade das ciências contribui em identificar e aproveitar as informações que serão empregadas para desenvolver, para analisar e transformar em informações estratégicas na sociedade da informação. E por fim, o bibliotecário reconhece as competências necessárias para desenvolver as atividades da unidade de informação e o processo de domínio, acesso e disseminação da informação.

\section{CONSIDERAÇÕES FINAIS}

A informação é o insumo de poder e solução, na medida em que através dela se tem alternativas às necessidades de conhecimento que por ventura surjam, em quaisquer sentidos, de apenas curiosidade até tomadas de decisões no trabalho e na própria vida do ser humano.

As diferentes características dos conhecimentos envolvem especificidades de discernimento e aplicação, porém a principal característica dos conhecimentos é a necessidade do homem em desenvolvê-los, descrevê-los, usá-los e transmiti-los. Dessa forma, é a habilidade humana que possibilita a sobrevivência do conhecimento. A capacidade do homem em criar e interagir revela a competência de buscar soluções, de saber fazer.

A característica principal de competência é a responsabilidade da tomada de decisão que relaciona a inteligência de ação aos conhecimentos adquiridos em constante mutação. Nesta perspectiva, observa-se que as mutações rotineiras na execução de tarefas exigem pessoas com competências múltiplas, essencialmente mobilizadas quanto ao imprevisto nas situações profissionais e sociais, ao invés de somente preparados para tarefas e cargos.

O bibliotecário reflete e se questiona sobre características e competências esperadas em um profissional moderno. Devido à diversidade crescente e constante dos sistemas de informação, práticas e perfis profissionais na sociedade da informação é preciso revisar e atualizar as respectivas competências para as várias atividades de trabalho, tanto para qualificar suas habilidades profissionais, quanto para auxiliar o desenvolvimento da organização em seu meio interno e externo.

As relações entre seres humanos sempre visualizam um processo em construção, pois a comunicação em diversas formas, com abrangentes dialéticas, símbolos e sinais, dissemina e resgata constantemente etapas da realidade. As várias idéias que se tornam senso comum são propulsoras das transformações e da dialética de uma sociedade, 
traçando um caminho de reflexão e atuação circunstancial na formação de sua representação social.

Em suma, o bibliotecário da UFAM apresenta muitos aspectos positivos de dedicação e adaptação ao novo cenário, onde a biblioteca está inserida. $O$ profissional tem procurado cumprir seu papel social e se atualizar profissionalmente, acompanhando as mudanças surgidas em suas atividades, em busca de superar suas limitações, priorizar e adequar seus serviços às necessidades de informação dos usuários e de trabalho. Compreende a interação de suas ações com os objetivos da biblioteca, bem como os da instituição, junto à prestação de serviços a essa comunidade universitária, estendendo-se à comunidade em geral, como parte integrante que é da sociedade.

Destacam-se alguns pontos, mencionados pelos bibliotecários, que impõem obstáculos ao desenvolvimento dos próprios e da biblioteca, como: dificuldade de comunicação e de compartilhamento da informação e do conhecimento; carência de pessoal qualificado em todos os ambientes de trabalho em quantidade suficiente; ausência de um plano de desenvolvimento formal e continuado para o bibliotecário; deficiência na articulação em equipe profissional e escassez de investimentos e manutenção em equipamentos e materiais adequados e eficazes. Esta ressalva tem o intuito de contribuir com pontos de partida na busca de planejamento para soluções satisfatórias ao desenvolvimento da biblioteca.

$\mathrm{Na}$ mesma perspectiva, ressaltam-se alguns fatores de competência no DSC deste profissional: a personalidade, o caráter e o amor à profissão; a união do conhecimento específico - habilidades práticas, técnicas e cognitivas - e o geral do ambiente e de experiências - trâmites, rotinas, ações e vivência-; a criatividade e o comprometimento pessoal; a atualização continuada profissional e social; adaptabilidade à realidade flutuante e a seu papel social; a capacidade de planejar, executar, inovar para evitar ou solucionar problemas; o senso crítico e a sensibilidade; a responsabilidade; a ética, o equilíbrio; a educação doméstica; ser agente facilitador do acesso à informação, entre outras tantas citadas.

\section{REFERÊNCIAS}

ARARIPE, Fátima Maria Alencar. Bibliotecário - profissional da informação (Re)desenhando o perfil a partir da realidade brasileira: proposta para os países do Mercosul. In: ENCUENTRO DE DIRECTORES Y SEGUNDO DE DOCENTES DE LAS ESCUELAS DE BIBLIOTECOLOGÍA DEL MERCOSUR, 3, Santiago, Chile, Octubre 1998. Santiago, Chile: Universidad Tecnológica Metropolitana, 1998. p. 105107. Disponível em: $<$ http://www.utem.cl/deptogestinfo/20.doc $>$. Acesso em: 20/04/2003.

ARRUDA, Maria da Conceição Calmon; MARTELETO, Regina Maria; SOUZA, Donaldo Bello de. Educação, trabalho e o delineamento de novos perfis profissionais: 
bibliotecário em questão. Ciência da informação, Brasília, v. 29, n. 3, Dezembro 2000. Disponível em: $<$ http://www.scielo.br/scielo.php.htm>. Acesso em: 27/02/2002.

BARBOSA, Ricardo Rodrigues. Perspectivas profissionais e educacionais em biblioteconomia e ciência da informação. Ciência da informação, Brasília, v. 27, n. 1, 1998. Disponível em: <http://www.scielo.br/scielo.php.htm>. Acesso em: 27/02/2002.

BELL, Daniel. As Dimensões do conhecimento e da tecnologia: a nova estrutura de classes da sociedade. In: Advento da sociedade pós-industrial: uma tentativa de previsão social. São Paulo, Cultrix, 1977. p.191-301.

BERGER, Peter L.; LUCKMANN, Thomas. A construção social da realidade: tratado de sociologia do conhecimento. 12. ed. Petrópolis, RJ : Vozes, 1995.

BLATTMANN, Úrsula et al. A aprendizagem, a biblioteca e a Internet. In:

(Org.); FRAGOSO, Graça Maria (Org.). O zapear a informação em bibliotecas e na Internet. Belo Horizonte : Autêntica, 2003. p. 27-39.

BURKE, Peter. Uma história social do conhecimento: de Gutenberg a Diderot. Rio de Janeiro: Zahar, 2003.

DE MASI, Domenico. O futuro do trabalho: fadiga e ócio na sociedade pós-industrial. 7. ed. Rio de Janeiro: José Olympio, 2003.

DURKHEIM, Émile. As regras do método sociológico: texto integral. São Paulo, SP: Martin Claret, 2003.

ELIAS, Norbert. Envolvimento e alienação. Rio de Janeiro : Bertrand Brasil, 1998.

ELIAS, Nobert. O processo civilizador : uma história dos costumes. Rio de Janeiro, RJ : Jorge Zahar, 1994. v. 1.

ENCUENTRO DE DIRECTORES DE ESCUELAS DE BIBLIOTECOLOGÍA Y CIENCIA DE LA INFORMACCION DEL MERCOSUR, 4., maio 2000 Montevideo. In : VALENTIM, Marta Pomim (Org.). Profissionais da informação: formação, perfil e atuação profissional. São Paulo : Polis, 2000. p.17-21. Anexo 3.

FREIDSON, Eliot. Renascimento do profissionalismo: teoria, profecia e política. São Paulo: Ed, da Universidade de São Paulo, 1998.

JODELET, Denise. Representações sociais: um domínio em expansão. In:

Representações sociais. Rio de Janeiro : Ed. da Universidade Estadual do Rio de Janeiro, 2001. p.17-44.

LEFÈVRE, Fernando ; LEFÈVRE, Ana Maria Cavalcanti. O discurso do sujeito coletivo: um enfoque em pesquisa qualitativa (desdobramentos). Caxias do sul, RS : Ed. da Universidade de Caxias do Sul, EDUCS, 2003.

MATTELART, Armand; MATTELART, Michèle. História das teorias da comunicação. 6. ed. São Paulo: Loyola, 2003.

MOSCOVICI, Serge. Representações sociais: investigações em psicologia social. 2. Ed. Petrópolis, RJ: Vozes, 2004.

NINA, Renée Rosanne Vaz. Profissional da informação: o bibliotecário e suas representações das competências profissionais e pessoais para atuar em bibliotecas. 2006. 257f. Dissertação (Mestrado em Ciência da Informação) Programa de Pós-Graduação em Ciência da Informação. Universidade Federal de Santa Catarina, Florianópolis, 2006.

POLANYI, Michael. The Tacit dimension. Gloucester, Mass., USA : Peter Smith, 1983.

PROBST, Gilbert; RAUB, Steffen; ROMHARDT, Kai. Gestão do conhecimento: os elementos construtivos do sucesso. Porto Alegre, RS: Bookman, 2002. 
SISTEMA DE BIBLIOTECAS DA UNIVERSIDADE DO AMAZONAS (SISTEBIB). Regimento Interno do SISTEBIB. Manaus, 1997.

SVEIBY, Karl Erik. O que é conhecimento? O que é competência?. In: A nova riqueza das organizações: gerenciamento e avaliando patrimônios de conhecimento. 7. ed. Rio de Janeiro: Campus, 1998. p. 35-46.

TARAPANOFF, Kira ; ARAÚJO JÚNIOR, Rogério Henrique de ; CORMIER, Patrícia Marie Jeanne. Sociedade da informação e inteligência em unidades de informação. Ciência da informação, Brasília, v. 29, n. 3, p. 91-100, set./ dez. 2000. Disponível em: $<$ http://www.scielo.br/scielo.php.htm>. Acesso em: 05/08/2003.

VALENTIM, Marta Lígia Pomim. Formação: competências e habilidades do profissional da informação. In:

(Org.). Atuação profissional na área de

informação. São Paulo, SP: Polis, 2004. p.117-132.

(Org.). O Profissional da informação: formação, perfil e atuação profissional.

São Paulo : Polis, 2000.

VIEIRA, Anna da Soledade. Conhecimento como recurso estratégico empresarial. Ciência da informação, Brasília, v.22, n.2, p.99-101, maio/ ago. 1993. Disponível em: $<$ http://www.scielo.br/scielo.php.htm>. Acesso em: 05/08/2003.

ZARIFIAN, Philippe. O modelo da competência: trajetória histórica, desafios atuais e propostas. São Paulo: SENAC/SP, 2003.

Objetivo competência: por uma nova lógica. São Paulo: Atlas, 2001.

\begin{abstract}
The objective of the study was know the representations of competences socially built by the professional of the library information inserted in the present setting of the blast informational, consequence of the technological innovations and of the globalization of the information. These representations were collected next to the active professionals in the libraries of the Universidade Federal do Amazonas (UFAM), having for theoretical base the Social constructionism treated by Berger and Luckmann (1995), the Theory of the Social Representations presented by Moscovici (2004) and complemented by the theory of the Civilizing Process of Elias (1994). Methodological, carried out itself to research in two phases. In the first one, utilized itself a questionnaire as data collection instrument for characterization and highlight of the sample of the research. In the second one, utilized itself a script for interview the sample and proceed to the analysis of discourse. Like this, it employed itself to technical of the Collective subject discourse (DSC) treated by Lefèvre and Lefèvre (2003) and theoretical recommendations of Elias (1998). The analysis of discourse, qualitative and exploratory in the collection of the manifestations and opinions of the librarian, enabled presentation of the DSC individual of each question that finally itself mix for constitute the DSC unique about the competences that the librarian perceives and manifest with property. As result standed out some factors of competence of this DSC: the personality, the character and the love to the profession; the union of the knowledge, values and experiences; the creativity, the personal compromise and the work in team; the updating continued professional and the adaptability to the floating reality and to their social paper, in the meantime others cited
\end{abstract}


KEYWORDS: Information professional. Competence. Social representation.

Librarians of university - Manaus, AM.

Originais recebidos em: 14/11/2007

Texto aprovado em: 13/03/2008

Nota: Este artigo foi produzido a partir da dissertação de Mestrado "Profissional da informação: o bibliotecário e suas representações das competências profissionais e pessoais para atuar em bibliotecas", defendida em 2006 no Programa de Pós-Graduação em Ciência da Informação da Universidade Federal de Santa Catarina, realizada sob a orientação do Professor Francisco das Chagas de Souza. 